Research Article

\title{
Estimation of ulna length as a predictor of height in Nepalese female adult population: An anthropometric study
}

\author{
Rajendra Prasad Sah ${ }^{1 *}$, Ravi Kumar Bhaskar ${ }^{2}$ \\ MB Kedia Dental College Birgunj, Nepal
}

${ }^{1}$ Professor, Department of Anatomy, MB Kedia Dental College, Birgunj, Nepal.

${ }^{2}$ Assistant Professor, Department of Community Medicine, National Medical College, Birgunj,Nepal.

\begin{abstract}
Background and Objectives: Stature estimation has a valuable importance for the anatomist, anthropologist and the forensic experts. Long bones are usually used for the estimation of individual height for the said purpose since 1952. The purpose of this study is to formulate a linear regression equation for the estimation of the stature of living female adult population from the length of ulna.
\end{abstract}

Materials and Methods: This research was conducted at M.B. Kedia Dental College Birgunj on 150 subjects who were chosen from among the patients and their attendants in the OPD. The height was measured from the crown to the heel and the length of the ulna was measured from the tip of the olecranon process to the tip of the styloid process. The recorded data was calculated by the standard statistical software.

Results: The correlation coefficient $(\mathrm{r})$ was found to be $0.55(\mathrm{p}<0.001)$ for the left ulna with stature and it was $0.463(\mathrm{p}<0.001)$ for the right ulna with stature after analyzing the data. Supportive regression equations and scatter-plot diagrams could successfully interpret the height from the ulnar length of the population.

Conclusion: The ulna length can be used for estimating the height of an individual. The regression equation which were proposed in this study will be useful for forensic esperts, clinicians, anatomists, archeologists, and anthropologists . Such evidence provides the investigator to gauge that aspect of an individual's physical description.

Key words: Forensic experts, Height, Stature ,Ulna

\section{INTRODUCTION}

Stature estimation from different parts of the skeleton of the human body is an area of interest to anatomists, anthropologists, forensic experts and clinicians. An indirect estimation can be done by correlating the height with other skeletal parameters in case 
of bedridden, old or frail patients, or in patients who have limb and/ or vertebral column deformity. The ulna has easily identifiable surface landmarks which make the measurements possible in compromised postures, than in any other bones. Therefore, it can be utilized to formulate the height indirectly [1]. Height is one of the factors in the description of an individual which varies with race, age sex, heredity, climate and nutritional status. Each racial group needs a separate formula for the estimation of stature [2]. Many of the previous workers worked on cadavers or on skeletal remains [3].

According to Trotter $\mathrm{M}$ et al. there is an increase in the height of $2.5 \mathrm{~cm}$ after death, when the measurement is taken in the recumbent posture [5].Since over half of the century, the stature estimation has been linearly regretted with the length of the different long bones, especially for which the percutaneous measurement could be taken, like the ulna, the tibia, etc. The linear regression equation of the height on the ulna length has a definitive advantage over that of the tibial length, as it can be useful in the cases where the lower extremities are deformed [6]. Even the ulna length was proven to be superior to the arm span measurement and the hand length in predicting the height [8].

The works of different researchers have postulated the linear regression of the height of an individual with the percutaneous ulna length $[10,11]$ both in the Indian and the international context. The ulna is a long bone often used for body height estimation it lies parallel in the fore arm with their ends fairly superficially placed. Prismatic in form placed at the medial side of the fore arm. Ulna is broader proximally and narrower distally.
Ossification of ulna starts at the $8^{\text {th }}$ fetal week of life and proximal epiphysis fuses with the shaft in the14th year of life in females and $16^{\text {th }}$ year in males. The distal epiphysis unites with the shaft in $17^{\text {th }}$ year of life in female and18th year of male.

\section{MATERIALS AND METHODS}

The research was conducted at MB Kedia Dental College Birgunj after taken approval from the Ethical Committee. All participants gave their informed consent prior to their inclusion in this study. The data collection was done more or less twice a week, which was spread over a period of 1 year January 2016 to December 2017. The present study comprised of a total of 150 females. Asymptomatic healthy medical persons belonging to various region of Birgunj area all residing in Nepal during time of study and their ages ranged between 20 to 29 years during which height remains more or less static are included in this study.

Slow decline in the height is known to occur as the age advances and therefore older subjects were not studied . Cases having bony growths, old fractures, any significant disease, orthopedic deformity, metabolic or developmental disorders which could have affected the general growth were excluded from study. In each case the height and length of right and left ulna were recorded.

The measurements were always taken at a fixed time, between $3-5 \mathrm{pm}$, to minimize diurnal variation. Stature is measured from crown to heel in standing in anatomical position having erect posture with head oriented in Frankfurt's plane with a standard height measuring instrument. The height of olecranon process to tip of styloid process with elbow flexed and palm spread over 
opposite shoulder. Measurements of length of right and left ulna were taken separately for calculation .The obtained values were used for the statistical analysis which was done by using the SPSS, version 12.0 software for the required analysis.

The prediction of a significant relationship amongst the pair of variables was determined by the "Correlation coefficient" i.e., Pearson's ' $r$ '. The relationship between the changes of a dependent variable (say, y) and an independent variable (say, $\mathrm{x}$ ) was ascertained by simple linear regression, with the "Regression coefficient (b)"; where the model of the regression equation was $y=a+b x$ (where $\mathrm{a}=\mathrm{y}$ intercept, when $\mathrm{x}=0$ ). As in every equation; a 95\% confidence interval (which was equivalent to1.96 standard deviation) was accepted and the standard error of regression (STE) was calculated. The final equation model was $\mathrm{y}=(\mathrm{a}+\mathrm{bx}) \pm(1.96$ x STE).

\section{RESULTS}

Table1: Height estimation from length of left ulna in adult Nepalese female $(\mathrm{N}=150)$ Table shows different statistical outcomes showing inter-relationship of left ulna length and height of a female individual.

\begin{tabular}{|c|c|c|}
\hline \multirow{2}{*}{} & $\begin{array}{c}\text { Independent } \\
\text { variable }\end{array}$ & $\begin{array}{c}\text { Dependent } \\
\text { Variable }\end{array}$ \\
\cline { 2 - 3 } & $\begin{array}{c}\text { Lt. ulna } \\
\text { length } \\
\text { cm }\end{array}$ & $\begin{array}{c}\text { Height } \\
\text { cm }\end{array}$ \\
\hline Mean & 25.49 & 154.59 \\
\hline Standard deviation & 1.29 & 5.61 \\
\hline $\begin{array}{c}\text { Correlation } \\
\text { coefficient (r) }\end{array}$ & $0.55(\mathrm{p}<0.001)$ \\
\hline $\begin{array}{c}\text { Regression constant } \\
\text { (a) }\end{array}$ & \multicolumn{2}{|c|}{94.11} \\
\hline $\begin{array}{c}\text { Regression } \\
\text { coefficient (b) }\end{array}$ & $2.37(\mathrm{p}<0.001)$ \\
\hline $\begin{array}{c}\text { Standard Error of } \\
\text { estimate (STExy) }\end{array}$ & \multicolumn{2}{|c|}{4.72} \\
\hline
\end{tabular}

Table-2: Height estimation from length of right ulna in adult Nepalese female $(\mathrm{N}=150)$ Table shows different statistical outcomes showing interrelationship of right ulna length and height of a female individual.

\begin{tabular}{|c|c|c|}
\hline \multirow{2}{*}{} & $\begin{array}{c}\text { Independent } \\
\text { variable }\end{array}$ & $\begin{array}{c}\text { Dependent } \\
\text { Variable }\end{array}$ \\
\cline { 2 - 3 } & $\begin{array}{c}\text { Rt.ulna } \\
\text { length } \\
\text { cm }\end{array}$ & $\begin{array}{c}\text { Height } \\
\text { cm }\end{array}$ \\
\hline Mean & 25.67 & 154.59 \\
\hline Standard deviation & 1.19 & 5.61 \\
\hline $\begin{array}{c}\text { Correlation coefficient } \\
\text { (r) }\end{array}$ & $0.463(\mathrm{p}<0.001)$ \\
\hline $\begin{array}{c}\text { Regression constant } \\
\text { (a) }\end{array}$ & \multicolumn{2}{|c|}{98.81} \\
\hline $\begin{array}{c}\text { Regression coefficient } \\
\text { (b) }\end{array}$ & $2.17(\mathrm{p}<0.001)$ \\
\hline $\begin{array}{c}\text { Standard Error of } \\
\text { estimate (STExy) }\end{array}$ & \multicolumn{2}{|c|}{4.99} \\
\hline \multicolumn{2}{|c|}{} \\
\hline
\end{tabular}

The mean of the heights was extrapolated as $154.59 \mathrm{~cm}$ with a standard deviation of 5.61 . Similarly, the means of the left and the right ulna lengths were calculated as $25.49 \mathrm{~cm}$ (with a Std. deviation of 1.29 ) and $25.67 \mathrm{~cm}$ (with a Std. deviation of 1.19) respectively (Table-1, 2).

The correlation coefficient ( $r$ ) of the height and the left ulna length was $0.55(\mathrm{p}<0.001)$, with a significant regression coefficient (b) of $2.37(\mathrm{p}<0.001)$. A supportive regression scatter-plot can also be made (Table-1, Fig-2). Similarly, the right ulna length was also found to bear a significant correlation with the height of the individual, with a correlation coefficient of $0.463 \quad(\mathrm{p}<0.001)$ and $\mathrm{a}$ regression coefficient $2.37 \quad(\mathrm{p}<0.001)$ respectively.

Here also, a supportive scatter-plot could be made, thus signifying the interpretation (Table-2, Fig-3). Thus, the regression PL; Estimated Height $(\mathrm{cm})=58.72+3.89 \mathrm{x}$ Right ulna length $(\mathrm{cm}) \pm 9.78$. 


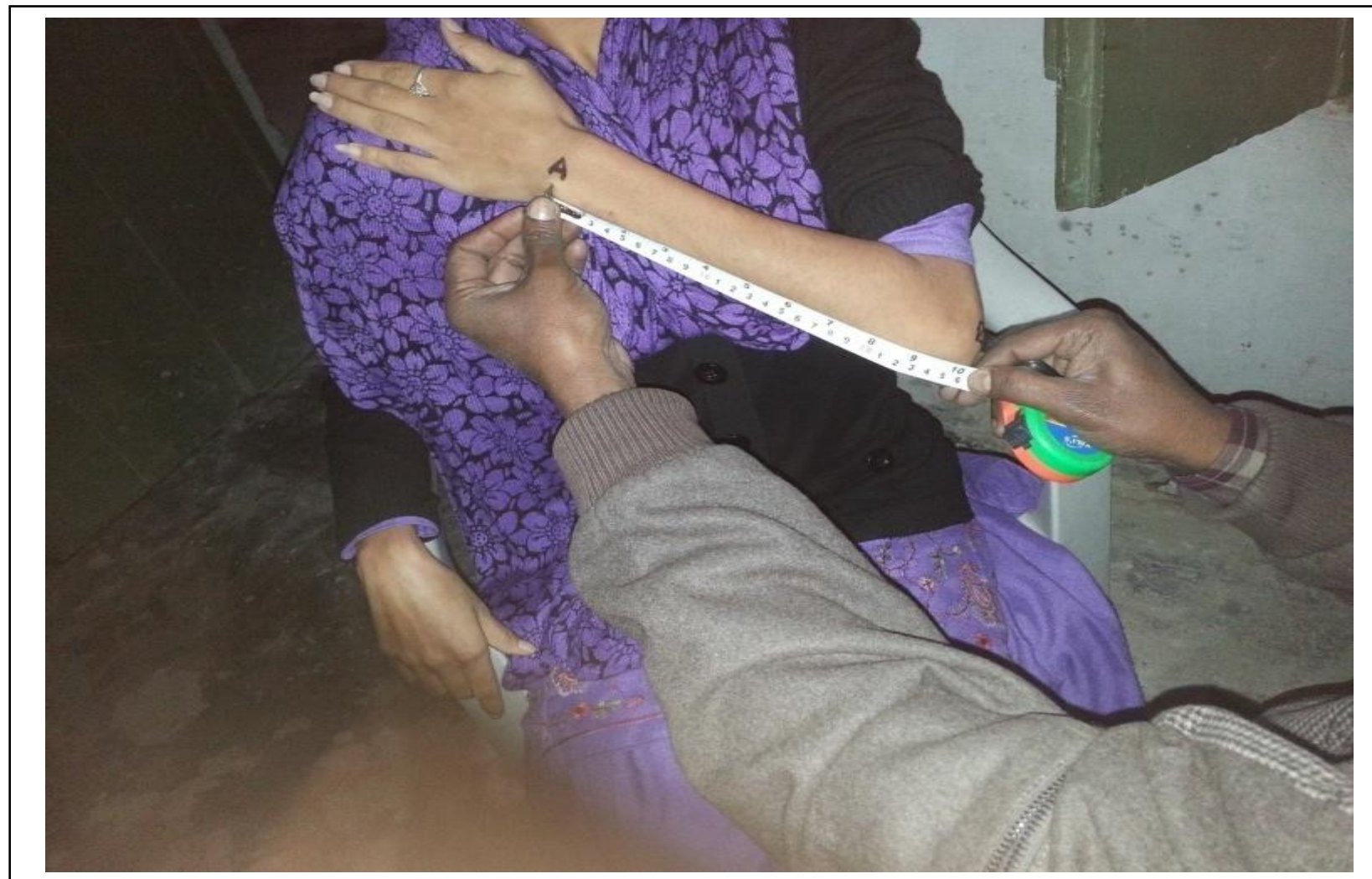

Fig-1: Figure showing the measurement of ulna length in adult female participant. Tip of the olecranon process is marked as $B$ and the ulna styloid process is marked $A$. The length $A$ ? $B$ demarcates the ulna length.

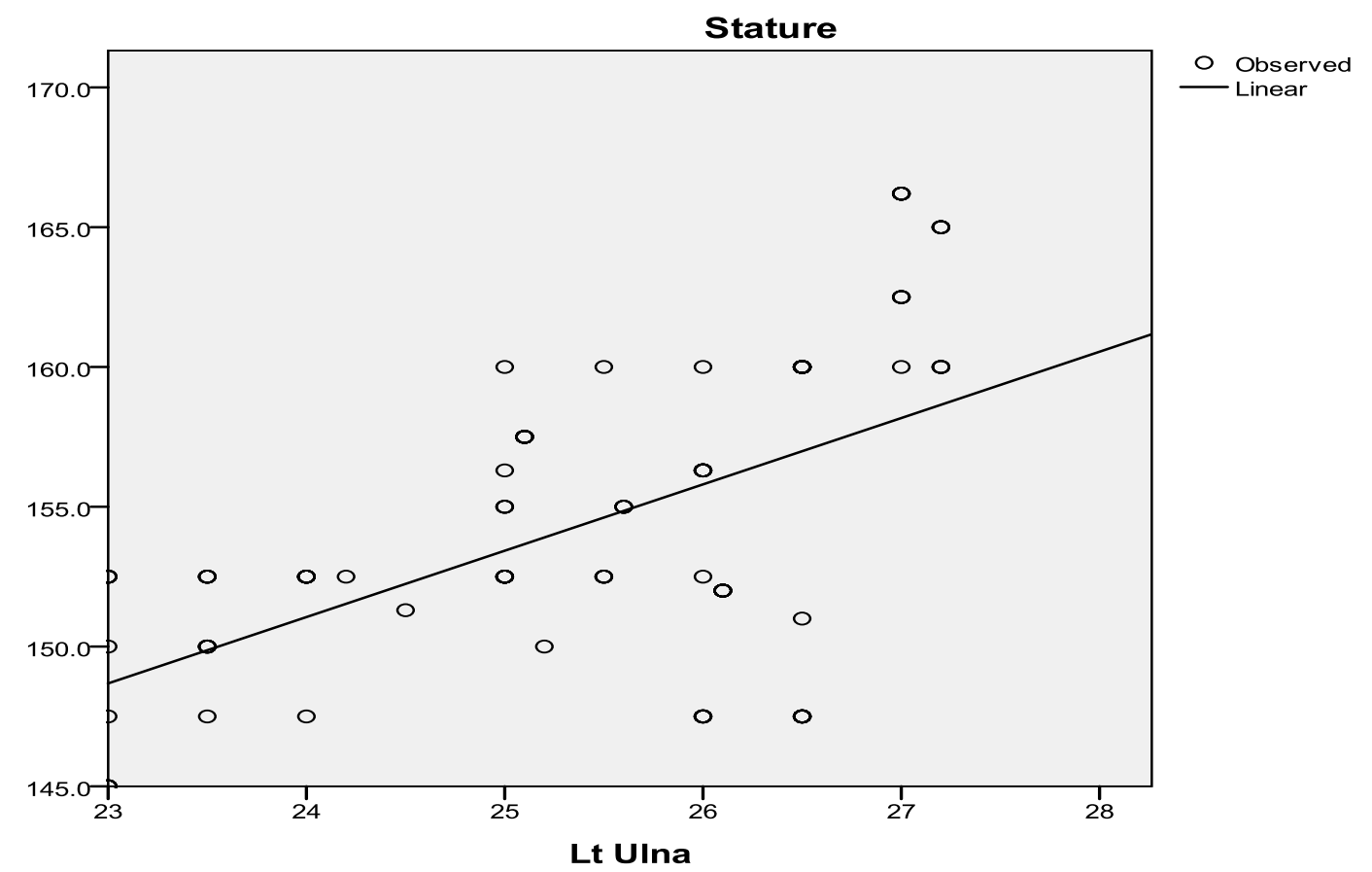

Fig 2. Graphical representation of interpretation of height of a female from length of left ulna $(\mathrm{N}=150)$.The graph shows showing inter-relationship of left ulna length and height of a female individual 


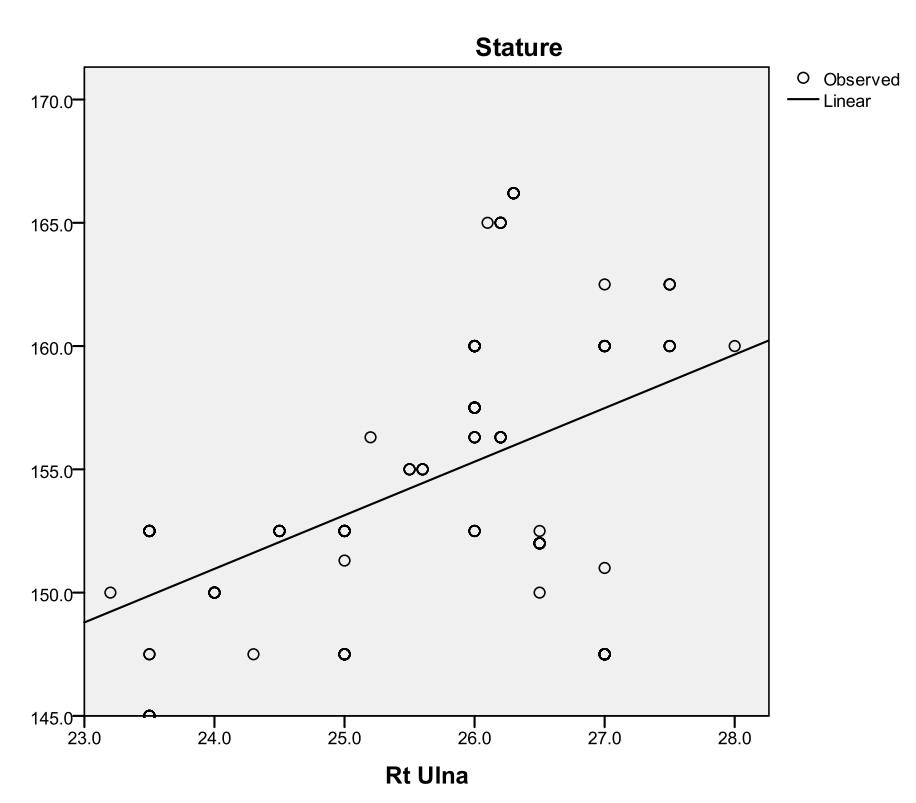

Fig-3: Graphical representation of interpretation of height of a female from length of left ulna ( $N=150)$.The graph shows showing inter-relationship of left ulna length and height of a female individual.

\section{DISCUSSION}

In the present study, the correlation coefficient ( $\mathrm{r}$ ) of the height and the length of the left ulna was 0.55 and that for the right ulna was 0.463 . The value of $r$ implied that there was a positive correlation. This implied a significant contribution of the length of the ulna towards the height. The simple linear regression equation which has so far been derived can be used for the estimation of the height. Our findings are at par with the findings of the previous researchers, as were reported in 1952 estimated the stature of American whites and negroes from the ulna with linear regression equations [5].

A study which was done by discussed the regression equation and the mathematical and the anatomical method of estimating the living stature from the long limb bones in the South African population [6]. The reports of from Mauritius and those of Barbaosa from
Portugal also found the linear regression model to depict an individual's stature from the percutaneous ulnar length $[10,11]$. India worked on a population of 258 in north Bihar, whose ages ranged from 12 to 21 years, for the estimation of the height from the surface anatomy of the long bones e.g. the tibia and the ulna [7].

The ulna mean multiplication factor was comparable in all the series. They claimed that the multiplication factor was a better guide for the calculation of the height, when it was not definitely known as to which part of the country the individual belonged. A similar study was done in Delhi in 1999 [9].

The correlation coefficient $(r=0.619$ for males and 0.584 for females) and the regression equation formula for the estimation of stature by using the upper arm length among the living population of the Maring tribes of the Pallel area in the Chandel district, Manipur [8]. In the Bengalee 
population postulated the height estimation in males from the ulna [11]. The present study could high light such a relationship in females .Since the height of an individual progressively increases upto a certain age (till adolescence) and then decreases after a certain age due to vertebral column erosion, so the inclusion of a wider range of age groups could overcome its limitation for its applicability of the regression model.

\section{CONCLUSION}

The regression equation has a valuable importance in the clinical practice and in medico-legal, anthropological and archeological studies, where the total height of a subject can be calculated if the ulna length is known.

\section{LIMITATION}

A more accurate estimation of the average body height and its prediction utilizing length of the ulna measurements in Nepalese adults would require a larger sample with sufficient geographical and social heterogeneity or a national survey that measures the whole population. Thus, the obvious limitation of this research study was the composition of the measured sample that consisted of population from different ethical communities.

\section{ACKNOWLEDGEMENT}

Authors would like to thank all the participants of this study and MB Kedia Dental College Birgunj for providing approval for conducting this research. Faculty members of department of Anatomy of MB Kedia Dental college are acknowledged for their coordination during this research.

\section{AUTHOR'S CONTRIBUTION}

RPS- Planning, Research and preparation of manuscript; RKV-Data analysis and revision of manuscript

\section{SOURCE OF SUPPORT}

None

\section{CONFLICT OF INTEREST}

There is no conflict of interest.

\section{REFERENCES}

1. Pearson K. A mathematical contribution to the theory of evolution. On the reconstruction of the stature of the prehistoric races. Philos Trans R Soc. 1898 London ; Series A 192: 169-244.

2. Trotter M, Glesser GC. Estimation of stature from the long bones of American whites and negroes. Am J Phy Anthropol 1952; (10): 463-514.

3. Celbis O, Agritmis H. Estimation of the stature and the determination of sex from the radial and the ulnar bone lengths in a Turkish corpse sample. Forensic Sci Int 2006 May 10; 158(23):135-9. Epub 2005 Jun 28. (available in http//:www.pubmed.gov. accessed on 23 June 2012).

4. Joshi NB, Patel MP, Dongre AV. Regression equation of the height from the ulnar length. Ind J Med Res 1964; 52:1088-91.

5. Ilayperuma I, Nanayakkara BG, Palahepitiya KN. A model for the reconstruction of the personal stature, based on the measurements of the foot length. Galle Med J 2008; 13:6-9.

6. Lundy JK. The mathematical versus anatomical methods of stature estimation from the long bones. Am J Forensic Med Pathol 1985 ;(6) No.1: 73-76.

7. Lal CS, Lala JK. Estimation of height from the tibial and the ulnar lengths in north Bihar. J Indian Med Assoc 1972 Feb 16; 58 (4) :120-21.

8. Nath S , Krishan G. Determination of stature by using the percutaneous measurement of the upper and the lower limb bone among the Hindu females of Delhi. J Anthropol Survey Ind 1990;(39): 151-66.

9. Devi S, Das H, Purnabati BK, Singh SD, Devi J. Estimation of stature from the upper arm length among the Marings of Manipur. Ind Med J Aug 2006;100: (8): 271-73.

10. 10.Mondal M, Jana TK, Das J, Biswas S. Use of the length of the ulna in the estimation of stature in living adult males in the Burdwan district and in the adjacent areas of West Bengal. J Anat Soc Ind 2009; 58(1): 16-19.

11. Agnihotri AK, Kachhwaha S, Jowaheer V, Singh AP. Estimating stature from the percutaneous length of the tibia and the ulna in an Indo-Mauritian 
population. Forensic Sci Int 2009 May 30; 187(13):109.e1-3. Epub 2009 Mar 14. (available in http//:www.pubmed.gov. accessed on 23 June 2012).

12. Barbosa M, Stratton RJ, Lafuente E, Elia M. Using the ulnar length to predict the height in English and Portuguese patient populations; European Journal of Clinical Nutrition 2012; 66: 209215;doi:10.1038/ejcn.2011.177; published online 12 October 2011.

13. Hubig M, Büttner A, Kuznik J, Penning R, Graw M. Sex determination and estimation of stature from the long bones of the arm. Forensic Sci Int 2001 Mar 1; 117(1-2):23-30. (available in http//: www.pubmed.gov. accessed on 23 June 2012).

14. Gauld LM, Kappers J, Carlin JB, Robertson CF. Height prediction from the ulnar length. Dev Med Child Neurol 2004; 46(7):475-80.

15. Telekka A. The prediction of the human stature from the long bones. Acta Anatomica 1950; (9):103-11.

\section{Correspondence to: \\ Dr. Rajendra Prasad Sah \\ Professor, \\ Department of Anatomy, \\ MB Kedia Dental College, Birgunj, Nepal. \\ Email: orthosurg2000@gmail.com}

